\title{
Chemical and Biological Treatment of Plastic Wastes by Bacteria Isolated from Contaminated Soils in Baghdad, Iraq.
}

\author{
Amal A. Hussein ${ }^{1 *}$, Mohammed Alzuhairi ${ }^{2}$ and Noor H. Aljanabi ${ }^{1}$ \\ ${ }^{1}$ Department of Applied Science, University of Technology, Baghdad-Iraq. \\ ${ }^{2}$ Material Engineering Department, University of Technology, Baghdad-Iraq. \\ *Corresponding Author: amelali71@yahoo.com.
}

\begin{abstract}
Due to the rapid increasing of polyethylene terephthalate (PET) used in industries, there are large of wastes quantities inter the stream per year which make a serious problem to water environment. In this work, the chemical treatment involve plastic bottles pieces mixed with $\mathrm{MgO}$ nano-catalyst, the result was white powder of polyethylene terephthalate (PET) which was used in this study. This work aims to isolate and screen bacterial isolates that able to degrade PET powder. Thirty eight bacterial isolates have been isolated from different waste disposal sites in Baghdad city. These isolates were screened on minimal salt media (MSM) plates according to clear zone method and the change in indicator color by using PET powder as the sole source of carbon and energy. According to morphological, biochemical characteristic, and analysis by Vitek 2 the most active isolates were identified as Acinetobacter baumannii.

[DOI: $10.22401 / \mathrm{JNUS} .21 .2 .19]$
\end{abstract}

Keywords: Polyethylene terephthalate powder, plastic wastes, Acinetobacter baumannii, biodegradation.

\section{Introduction}

Plastic is defined as the polymer (solid material) which becomes mobile by heating and thus can be turned into mold. Plastic is non-metallic moldable compound and the materials made from it, can be formed in almost any desired shape and later retain that shape. Plastic is used in packaging, disposable diaper backing, fishing nets, and agricultural films. It includes polymers such as polyethylene, polypropylene, polystyrene, poly (vinyl chloride), polyurethane, polyethylene terephthalate (PET), and nylon [1].

Plastic is the result of 20 century production. Basically, plastic was imitating and replacing natural products (lacquer, shellac, amber, horns, tusks, tortoise, shell), but today, it is largely synthetic material made from an extremely inexpensive but nonrenewable resource, crude oil [2]. Plastic development in the world has been started since 1930 with the occurrence of polyvinyl chloride (PVCA), polystyrene (PS), nylons, polyethylene (PET) and polypropylene (PP). Polymer addition and condensation was interred into markets in 1950 [3].

The use of plastic has become a part in all sectors of the economy. Infrastructure such as agriculture, building, and construction, telecommunication, consumer goods, packaging, health and medical are all high growth areas which will guarantee a growing demand for plastic. Plastic is the fundamental industry to hundreds of manufactured products used in our daily life such as automobile parts, televisions, refrigerators, other electrical goods, plastic furniture, defense products, agriculture pipes, woven sacks, packages, and sanitary.

Plastic plays an important role in many "short live" applications like packaging and these represent the main part of plastic wastes [4]. Because of its propagation in our environment, several communities are now more sensitive to the impact of discarded plastic on the environment, including deleterious effects on wildlife and on the aesthetic qualities of cities and forest.

\section{Material and Methods \\ Preparation of PET powder}

As a first step, $100 \mathrm{~g}$ of PET pieces were mixed with $116 \mathrm{ml}$ of ethylene glycol (EG) (4:1 EG, PET molar ratio) with $0.05 \%$ NanoMagnesium Oxide as a catalyst depending on the weight of PET at EG boiling point for 40 min until fully depolymerization. Treatment with heat involved complete condensation using refluxing unit in close system (zero material loss) using glass condenser cooling 
with water, then separated unreacted ethylene glycol out of mixture leaving the final form of PET [5]. Fourier transform infrared spectroscopy (FTIR) was used to confirm the formation of new functional groups or disappearance of functional groups in the polymer.

\section{Samples collection}

Ten plastic waste and soil samples were collected from four dumping sites in Baghdad city, between the periods December 2016 and March 2017 Table(1). The initial identification showed that these sites contain polluted plastic materials on their surface or buried in soil.

The samples were randomly collected from the soil superficially in depth $(5-10 \mathrm{~cm})$, using sterilized spatula then transferred into sterile bags, and stored until use at $4{ }^{\circ} \mathrm{C}$.

\section{Table (1)}

Four different soil samples were collected from different locations, within Baghdad city.

\begin{tabular}{|c||c||c||c||}
\hline No. & $\begin{array}{c}\text { Site of } \\
\text { samples }\end{array}$ & $\begin{array}{c}\text { Sampling } \\
\text { date }\end{array}$ & $\begin{array}{c}\text { Sampls } \\
\text { numbr }\end{array}$ \\
\hline \hline 1 & Abo-Dsheer & $2 / 12 / 2016$ & 3 \\
\hline 2 & Al-Mahmodia & $11 / 1 / 2017$ & 2 \\
\hline 3 & Al-Dorah & $20 / 2 / 2017$ & 2 \\
\hline \hline 4 & Al-Za'farania & $10 / 3 / 2017$ & 3 \\
\hline
\end{tabular}

Isolation of PET powder degrading bacteria

Enrichment culture technique was used to isolate the most active PET degrading bacteria. A stock was made from each sample $(1 \mathrm{~g}$ of soil added to $10 \mathrm{ml}$ distilled water) and incubated in a shaker incubator for 30 minutes at $37^{\circ} \mathrm{C}$, then $5 \mathrm{ml}$ of the stock was used to inoculate $100 \mathrm{ml}$ flasks containing mineral salts medium with $0.1 \%$ (wt. /v) PET powder, followed by incubation at $37^{\circ} \mathrm{C}$ at $150 \mathrm{rpm}$ for 7 days and this step was repeated twice for all samples. Optical density was measured after every incubation period at $600 \mathrm{~nm}$. Finally, 1 $\mathrm{ml}$ was taken from the third flask and spread over MSM-agar plates containing 0.1\% PET powder to isolate PET degrading bacteria; after 14 days of incubation at $37^{\circ} \mathrm{C}$, single colonies were picked and streaked on nutrient agar plates to be isolated and purified [6].

\section{Clear zone}

To detect the ability of PET degrading bacteria, solid-MSM with $0.1 \%$ of PET powder (wt. /v) were inoculated with loop full from each isolate in the middle of the agar plate and incubated for 7 days in $37^{\circ} \mathrm{C}$. After a period of incubation, the diameter of bacterial growth for each isolate was determined [7].

\section{Screening of polyethylene terephthalate powder degrading bacteria \\ Liquid MSM with PET powder}

Thirty eight isolates that showed the highest capability for PET biodegradation were tested for their ability to grow in liquidMSM with $0.1 \%$ (wt./v) PET powder. The density of the growth at $600 \mathrm{~nm}$ within 7 days of incubation period was determined [8].

\section{Emulsifying medium}

Polyethylene terephthalate emulsifying agar plates were inoculated with loop full of each pure isolate and spreaded on the middle of the agar plate, and they were incubated for 3 days $/ 37^{\circ} \mathrm{C}$. The change in color zone diameter around colonies growth was determined [9]. This medium was also used as liquid medium, the color changing and intensity was the indicator for PET powder degradation.

\section{Identification of PET degrading bacteria}

The most active bacterial isolate was selected depending on many factors, such as cell shape, its organization and the reaction with gram stain [10]. Biochemical tests were performed: sugar fermentation test, motility test, catalase, urease, production of oxidase, gelatin liquefying test, citrate utilization test, starch utilization test, Vogus-Proskauer test, methyl-red test and indole test.

\section{Results and Discussion}

Millions tons of PET bottles are desposed in the environment; therefore, industrial companies are trying to exploit these wastes in different manufacturing processes by converting into powder to facilitate the mixing of PET with other industrial materials. The conversion process was done by mixing PET pieces with EG and $\mathrm{MgO}$ Nano-catalyst which is an efficient catalyst to reduce the time of chemical reaction as Fig.(1) [11]. 

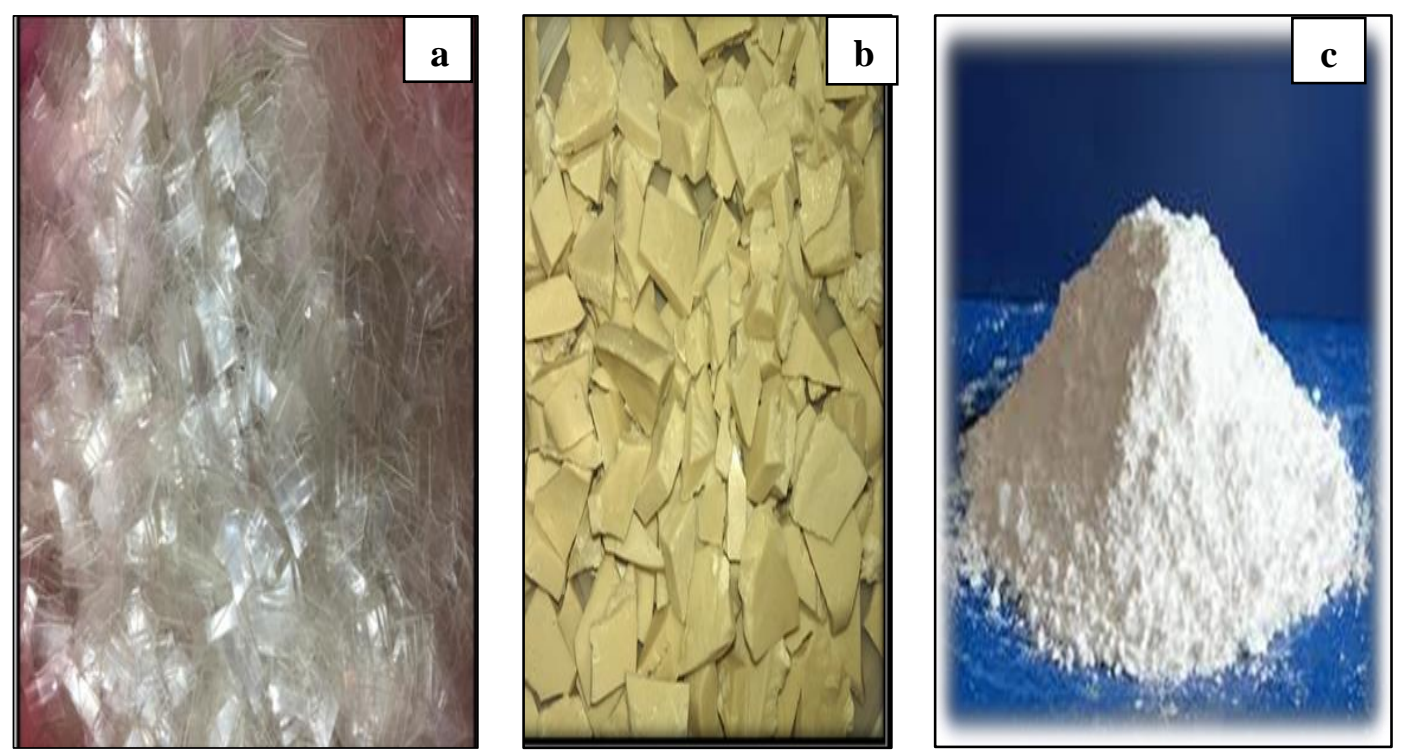

Fig.(1): Chemical conversion of plastic bottles into powder.

(a): plastic bottles pieces; (b): PET after chemical reaction; (c): the final form of DPET powder after washing.

The chemical reaction is shown in Fig.(2)

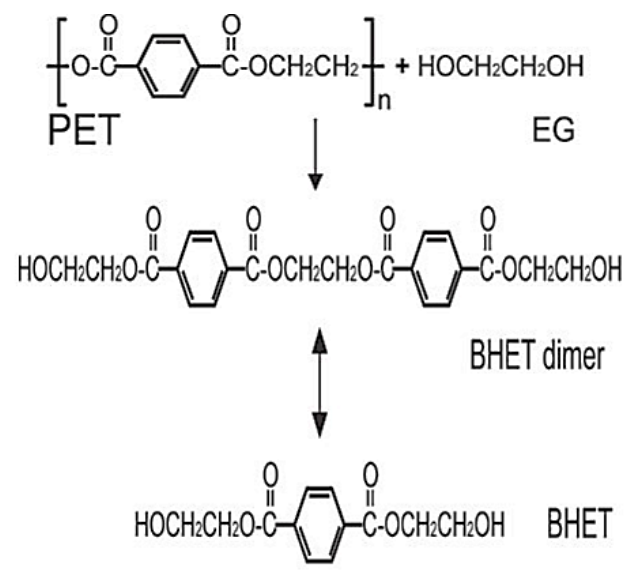

Fig.(2): Chemical reaction of PET depolymerization.

FTIR analysis was carried out at the labs of Nanotechnology advanced material research center/ University of Technology/ Baghdad using Fourier transform infrared spectrometer MB3000, as shown in Fig.(3). The difference between plastic bottles before and after the chemical treatment is shown.

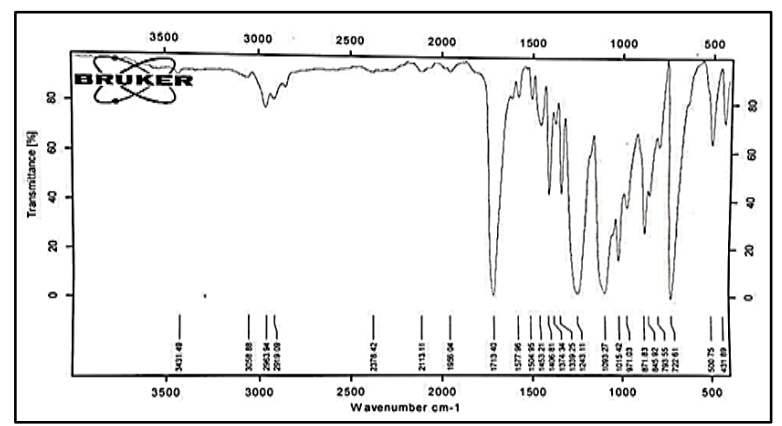

Fig.(3.a): FTIR spectrum for plastic bottles.

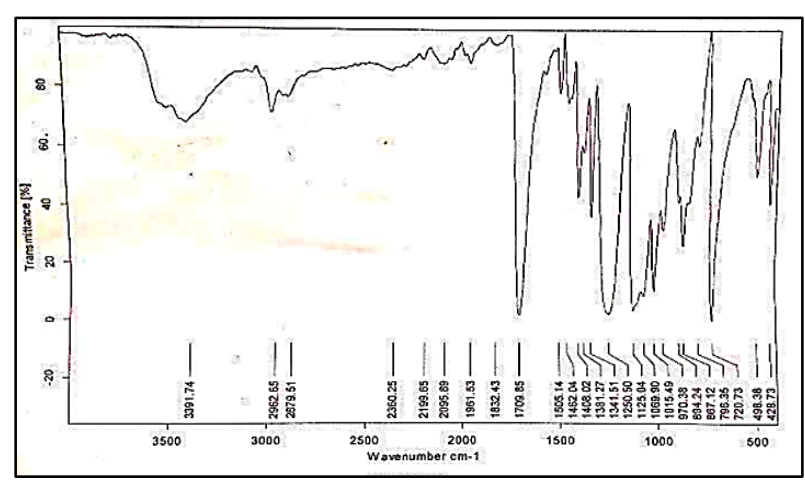

Fig.(3.b): FTIR spectrum for PET powder.

Fig.(3.a) exhibits the plastic bottles (pure PET), little $\mathrm{C}-\mathrm{H}$ group has appeared with no $\mathrm{O}-\mathrm{H}$, that match with the structure of PET mentioned below. The appearance of more $\mathrm{C}-\mathrm{H}$ and $\mathrm{O}-\mathrm{H}$ groups is the evidence for PET chemical degradation (glycolysis). The Glycoysed product PET of The FTIR spectrum of, absorption at $3391 \mathrm{~cm}^{-1}$ is shown in Fig.(3.b) due to the $\mathrm{OH}$ (inter molecular hydrogen bonds), $2879-2962 \mathrm{~cm}^{-1}$ for $\mathrm{C}-\mathrm{H}$ stretch, $1709 \mathrm{~cm}^{-1}$ for Carbonyl group (CO), $1125 \mathrm{~cm}^{-1}$ for asymmetrical C-O-C stretch and $518-875 \mathrm{~cm}^{-1}$ indicates of aromatic rings.

\section{Biological treatment \\ Isolation of PET degrading bacteria}

To isolate PET degrading bacteria, the soil samples were added in MSM medium and isolated by enrichment method with measuring the optical density after every incubation period as in Table (2). Thirty eight bacterial isolates were isolated and screened; they were 
obtained 10 soil samples contaminated with waste of plastic materials from different municipal landfill cites in Baghdad city at different periods from December 2016 until March 2017, as shown in Table (3). Al-Za'farania sample gave the largest number of isolates, were the soil is contaminated with hydrocarbons so we find isolates able to degrade the polymer which is a hydrocarbon material.

Table (2)

Optical densities values of soil samples after different incubation periods.

\begin{tabular}{|c|c|c|}
\hline No. & Sample symbol & O.D. Value (nm) \\
\hline \multicolumn{3}{|c|}{ For the first week } \\
\hline 1 & Control & 0.200 \\
\hline 2 & NH-A & 0.500 \\
\hline 3 & NH-B & 0.800 \\
\hline 4 & NH-C & 0.900 \\
\hline 5 & NH-D & 0.620 \\
\hline \multicolumn{3}{|c|}{ For the second week } \\
\hline 1 & Control & 0.201 \\
\hline 2 & "NH-A & 0.364 \\
\hline 3 & NH-B & 0.330 \\
\hline 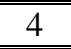 & NH-C & 0.355 \\
\hline 5 & NH-D & 0.500 \\
\hline \multicolumn{3}{|c|}{ For the third week } \\
\hline 1 & Control & 0.200 \\
\hline 2 & NH-A & 0.450 \\
\hline 3 & NH-B & 0.650 \\
\hline 4 & NH-C & 1.564 \\
\hline 5 & NH-D & 1.750 \\
\hline
\end{tabular}

Table (3)

Regions and periods of samples collection.

\begin{tabular}{||c|c||c||c||}
\hline No. & $\begin{array}{c}\text { Sample } \\
\text { regions }\end{array}$ & $\begin{array}{l}\text { Sampling } \\
\text { date }\end{array}$ & $\begin{array}{c}\text { Isolates } \\
\text { symbol }\end{array}$ \\
\hline \hline 1 & $\begin{array}{c}\text { Abo- } \\
\text { Dsheer }\end{array}$ & $2 / 12 / 2016$ & NH-A \\
\hline 2 & $\begin{array}{c}\text { Al- } \\
\text { Mahmodia }\end{array}$ & $11 / 2 / 2017$ & NH-B \\
\hline 3 & Al-Dorah & $20 / 2 / 2017$ & NH-C \\
\hline \hline 4 & $\begin{array}{c}\text { Al- } \\
\text { Za'farania }\end{array}$ & $10 / 3 / 2017$ & NH-D \\
\hline
\end{tabular}

\section{Clear zone test}

Out of 38 isolates, only 19 were grown efficiently on the MSM-agar medium within 15 days and form a clear zone around the growth. This indicates their possession of great enzymatic mechanism made them able to degrade the target polymer. No similar results for other researches were found. Results showed that Al-Za'farania (NH-D) isolates grow with a diameter of $3.25 \mathrm{~cm}$ as shown in Fig.(4), Table (3).

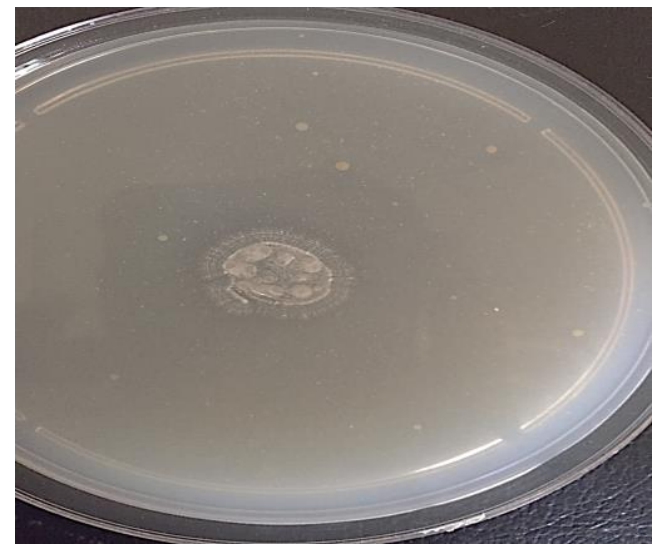

Fig.(4): Growth of bacteria on solid MSM with $0.1 \%$ (wt. /v) of PET powder.

Table (3)

Growth diameters of bacterial isolates on MSM-agar medium with DPET powder.

\begin{tabular}{|c|c||c||}
\hline No. & Isolates symbol & $\begin{array}{c}\text { Growth } \\
\text { diameter }(\mathbf{c m})\end{array}$ \\
\hline \hline 1 & NH-A1 & 2.4 \\
\hline \hline 2 & NH-A3 & 2.0 \\
\hline 3 & NH-A4 & 1.9 \\
\hline \hline 4 & NH-A6 & 1.5 \\
\hline 5 & NH-B2 & 2.0 \\
\hline \hline 6 & NH-B5 & 2.5 \\
\hline 7 & NH-B8 & 2.2 \\
\hline 8 & NH-B10 & 2.0 \\
\hline 9 & NH-B13 & 2.0 \\
\hline 10 & NH-C1 & 1.4 \\
\hline \hline 11 & NH-C4 & 1.8 \\
\hline 12 & NH-C7 & 2.7 \\
\hline 13 & NH-D1 & 3.25 \\
\hline 14 & NH-D3 & 2.1 \\
\hline 15 & NH-D4 & 2.4 \\
\hline 16 & NH-D7 & 2.4 \\
\hline 17 & NH-D8 & 1.5 \\
\hline 18 & NH-D11 & 1.3 \\
\hline 19 & NH-D12 & 1.9 \\
\hline \hline
\end{tabular}

\section{Screening of PET degrading bacteria}

\section{1- Emulsifying medium}

Isolates (19) which gave the highest diameter growth were screened on MSMbromocresol agar containing $0.1 \%$ of PET powder. On the other hand, this medium was 
used as liquid and solid medium to test the biodegradability of PET powder; it was prepared and sterilized then inoculated with the isolates then incubated in a shaker incubator for 3 days at $37^{\circ} \mathrm{C}, 150 \mathrm{rpm}$. Seven isolates succeeded to grow and degrade PET and as a result, the color of media was changed [12].

The seven bacterial isolates gave a clear observation of polymer degradation as indicated by the color change from purple to yellow. This refers to increasing acidity of the medium as a result of enzymatic action of bacteria that utilize the polymer into simplest material since the color changes from purple to yellow in acidic medium ensuring the production of acids due to the bacterial oxidation of polymer Fig.(5,6). Therefore, NH-D-1 isolate was chosen to be identified.

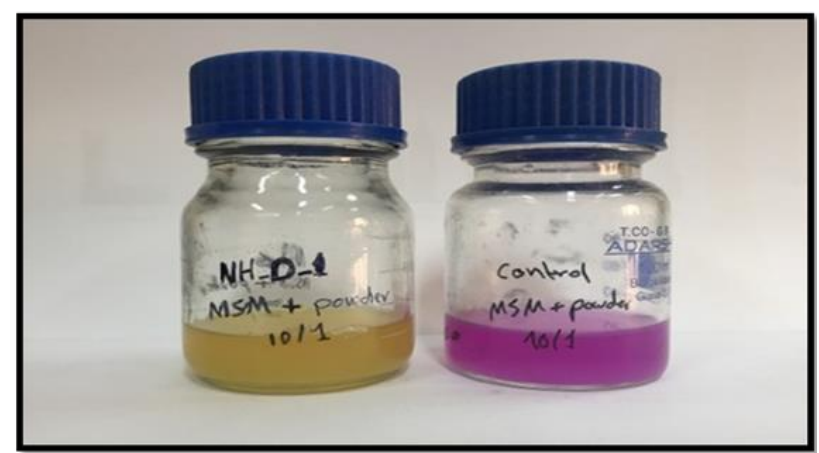

Fig.(5): The active isolate growing on liquid MSM containing PET powder with Bromocresol purple as indicator.

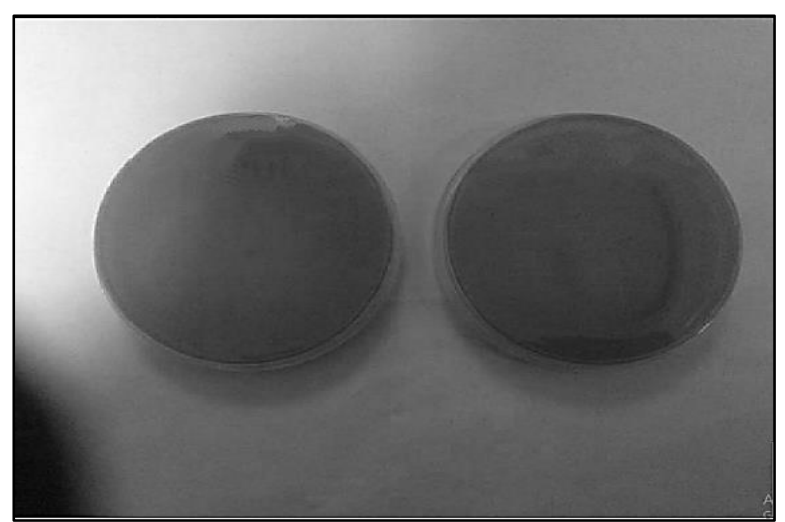

Fig(6): The active isolate growing on MSM agar containing PET powder with Bromocresol purple as indicator.
Table (4)

Growth diameters of PET powder degrading bacterial isolates on emulsifying medium.

\begin{tabular}{|c||c|c||}
\hline No. & $\begin{array}{c}\text { Sample } \\
\text { symbol }\end{array}$ & $\begin{array}{c}\text { Growth } \\
\text { diameter }(\mathbf{c m})\end{array}$ \\
\hline \hline$I$ & NH-A1 & $r .1$ \\
\hline$r$ & NH-A3 & 2.0 \\
\hline \hline$r$ & NH-B2 & 1.5 \\
\hline \hline$\varepsilon$ & NH-B8 & 2.0 \\
\hline 0 & NH-C7 & 1.5 \\
\hline$r$ & NH-D1 & 2.3 \\
\hline$r$ & NH-D7 & 1.2 \\
\hline
\end{tabular}

Identification of polyethylene terephthalate powder degrading bacteria

PET degrading isolate was chosen and identified depending on the results given after screening. The identification was done according to the characteristics (bio-chemical and morphological) of bacterial isolates.

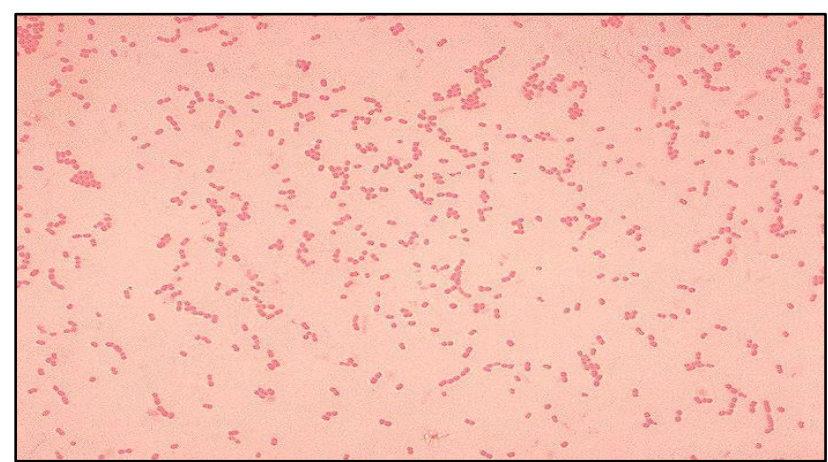

Fig.(7): The Microscopic Examination of Acinetobacter baumannii cells under light microscope $(100 \mathrm{X})$ with oil.

Microscopic and morphological observations showed that The bacterial isolate was gram negative, non-forming to spores, lactose fermenter, coccobacillary in shape, usually appears like pairs or single, non-motile as shown in Fig.(7). Results confirmed that the active isolate was Acinetobacter baumannii which isolated from soil contaminated with plastic bottles wastes. Table (5) includes the detailed morphological description, while biochemical tests 
Table (5)

Morphological characteristics of bacterial isolate.

\begin{tabular}{|l||l|}
\hline $\begin{array}{c}\text { Morphological test } \\
\text { name }\end{array}$ & Characters \\
\hline \hline Gram reaction & Negative \\
\hline \hline Cell shape & Coccobacilli \\
\hline Pigment production & Cream \\
\hline Motility test & Non-motile \\
\hline Spore location & Non-forming \\
\hline Colony surface & Convex \\
\hline Colony elevation & Raised \\
\hline \hline Colony margin & Entire \\
\hline Colony configuration & Circular \\
\hline
\end{tabular}

Table (6)

The biochemical tests of active bacterial isolate.

\begin{tabular}{||l||c||}
\hline \multicolumn{1}{|l||}{ Biochemical test name } & Result \\
\hline \hline Oxidase test & - \\
\hline Indol test & - \\
\hline \hline Gelatin hydrolysis & - \\
\hline \hline Starch hydrolysis & - \\
\hline \hline Citrate utilization & - \\
\hline Glucose fermentation & + \\
\hline Urease & + \\
\hline Voges - Proskauer test & - \\
\hline Methyl red & - \\
\hline Catalase test & + \\
\hline Sucrose & - \\
\hline Lactose & + \\
\hline
\end{tabular}

To complete the bacterial identification, Vitek-2 was used. It is an efficient technique to identify the bacterial isolates. Result confirmed our conclusions by biochemical tests. According to Vitek-2 technology, HN-D1 was identified as Acinetobacter baumannii of $99 \%$ probability, as shown in Fig.(8).

\section{Conclusions}

Depending on the results obtained from this study, the conclusions may be given:

1. Widespread studies on the degradation of plastics have been carried out in order to overcome the environmental problems associated with synthetic plastic waste. Biodegradation of plastics by microorganisms seems to be the most effective process to fight against plastic waste.

2. Soil samples from landfill dump of plastic waste considered an excellent source for polymer degrading bacteria.

3. PET can be degraded by microorganisms (biodegradation) like Acinetobacter baumannii, present in soil contains plastic waste. The method used in the present experiment is cost effective, easy to perform, and environmentally friendly.

4. The use of DPET powder in many construction industries is not the efficient recycling method due to the biodegradability of PET which have been proven in this study. 


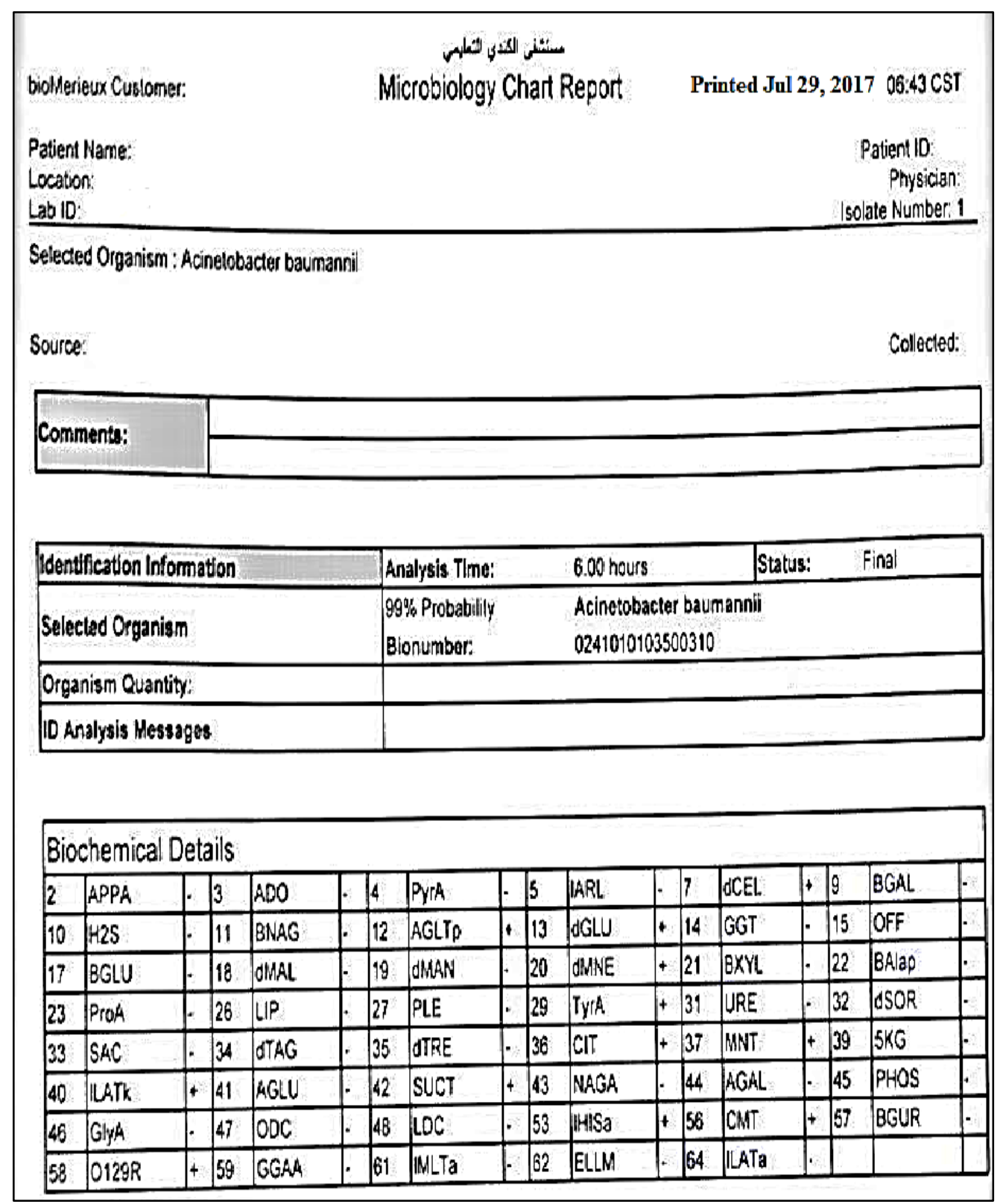

Fig.(8): The final characterization of the active isolate Acinetobacter baumannii using Vitek 2 technique.

\section{References}

[1] Seymour R. B. "Polymer Science before \& after 1899: Notable Developments during the lifetime of Maurtis Dekker", J. Macromol. Sci. Chem. A26. 1023-1023, 1989.

[2] Rochman C.M., Browne M.A., Halpern B.S., Hentschel B.T., Hoh E., Karapanagioti H.K., Rios-Mendoza L.M., Takada H., Teh, S. and Thompson R.C. Policy: Classify plastic waste as hazardous. Nature, 494(7436), 169-171, 2013.

[3] Datta P, K., Mishra K., and M. N. V. R. Kumar. Popular plastics and packaging, Mahindra Publishers, New Delhi, India. P. 73, 1998.
[4] Muller R. J., I. Kleeberg W. D. Deckwer. Biodegradation of polyesters containing aromatic constituents. J. Biotechnol. 86: 8795, 2001.

[5] Alzuhairi M.A.H., Al-Ghaban A.M. and Almutalabi S.N. Chemical Recycling of Polyethylene Terephthalate (PET) as Additive for Asphalt. ZANCO Journal of Pure and Applied Sciences, 28(2) 2016.

[6] Pan L. and Gu J.D. Characterization of aerobic bacteria involved in degrading polyethylene glycol (PEG)-3400 obtained by plating and enrichment culture techniques. Journal of Polymers and the Environment, 15(1), 57-65, 2007. 
[7] Usha R., Sangeetha T. and Palaniswamy M. Screening of polyethylene degrading microorganisms from garbage soil. Libyan agriculture research center journal international, 2(4), 200-204, 2011.

[8] Hussein A.A., Al-Mayaly I.K. and Khudeir S.H. Isolation, Screening and Identification of Low Density Polyethylene (LDPE) degrading bacteria from contaminated soil with plastic wastes. Journal, 1(4), 1-14, 2015.

[9] Sharon C. and Sharon M. Studies on Biodegradation of Polyethylene terephthalate: A synthetic polymer. Journal of Microbiology and Biotechnology Research, 2(2), 248-257, 2017.

[10] Ikada E. Electron microscope observation of biodegradation of polymers. Journal of environmental polymer degradation, 7(4), 197-201, 1999.

[11] Albertsson A.C., Erlandsson B., Hakkarainen M. and Karlsson S. Molecular weight changes and polymeric matrix changes correlated with the formation of degradation products in biodegraded polyethylene. Journal of Polymers and the Environment, 6(4), 187-195, 1998.

[12] Tsuji H. and Suzuyoshi K. Environmental degradation of biodegradable polyesters 1 . Poly (E-caprolactone), poly [(R)-3hydroxybutyrate], and poly (L-lactide) films in controlled static seawater. Polymer Degradation and Stability, 75(2), 347-355, 2002. 